\title{
Researches Regarding the Agrotehnic Behaviour of Perspective Elites Obtained at Research Station for Viticulture and Enology Blaj
}

\author{
Daniela POPESCU ${ }^{1 *}$, Maria ILIESCU ${ }^{1)}$, Cristian CRISTEA ${ }^{1)}$, Maria COMŞA ${ }^{1)}$ \\ ${ }^{1)}$ Reasearch Station for Viticulture and Enology, 2 Gh. Baritiu Street, Blaj, 515400, Romania, \\ ${ }^{*}$ Corresponding author, e-mail: hodordaniela@yahoo.com
}

Bulletin UASVM Horticulture 71(2) / 2014

Print ISSN 1843-5254, Electronic ISSN 1843-5394

DOI:10.15835/buasvmcn-hort:10673

\begin{abstract}
The Research Station for Viticulture and Enology Blaj (SCDVV Blaj), white a long tradition on improving wine grape varieties, was performed intraspecific hybridization and clonal selection in order to obtain new varieties and clones with superior qualities of provenance varieties. The hybrid elites that were tested in the yield trials of SCDVV Blaj were: 5-26 (Traminer roz x Iordană) and 11-26 (Fetească regală x Muscat Ottonel) and from the test field were selected the following clonale elites: 18-11 Pinot gris and 17-49 Fetească regală. These elites have been studied during 2012-2013 period and reported on a reference system consisting from control varieties: Traminer roz 60 Bl., Fetească regală 21 Bl., Pinot gris 34 Bl. The studied hybrid elites had good behavior with good value sugar / acidity / production ratio. Of clonal elites was remark 18-11 from qualitative point of view since has accumulated the greatest amount of sugars, with a good sugar / acidity ratio. Regarding the productivity, it is noted 17-49 clonale elite who obtained the highest yield. Because from clonale elite 18-11 Pinot gris and 5-26 hybrid elite can be obtained superior quality wines (DOC category), with a potential alcoholic over $12.5 \%$ vol. even in less favorable climatic conditions for vine culture, these will be proposed for homologation.
\end{abstract}

Keywords: agrotehnic behaviours, clonale elites, hybrid elites, quality, wine grape genotype

\section{INTRODUCTION}

Knowledge of plant development is crucial in viticulture for site and cultivar selection, with the purpose of a rational vineyard establishment planning (Tóth-Lencsés et al., 2014).

Creating through genetic improvement works of varieties suitable or at least tolerant to the main specific diseases, capable of providing higher quality grape production, appears as a real alternative to increase the profitability of grapevine culture and reducing grape production and environment pollution, a sure way of achieving organic viticulture (Iliescu et al., 2010; Călugăr et al., 2010; Călugăr, 2011; Wiedemann-Merdinoglu et al., 2014).

SCDVV Blaj has a long tradition on research for improving wine grape varieties (Oprea and Moldovan, 2007), an activity that continues as the assortment for wine and table grapes must be enhanced with grape varieties with superior qualities and resistance to disease and frost, requested more intensive by those who establishes vineyards. The highest percentage in the ampelographic collection is owned by grape varieties for white wines.

Maintaining economic characteristics and qualities useful to superior parameters requires continuous selection and the use for breeding only those specimens that express faithfully the agrobiological particularities value. In this way is realized the diminishing of genetic vulnerability process on the one hand, and restoring the productive potential and the initial quality on the other hand (Sestras, 2004).

\section{MATERIALS AND METHODS}

In the yield trials of SCDVV Blaj were tested hybrid elites: 5-26 (Traminer roz x Iordană) and 11-26 (Fetească regală x Muscat Ottonel) and from 
the test field were selected clonale elites: 18-11 Pinot gris and 17-49 Fetească regală. These elites have been studied during 2012-2013 period and reported on a reference system consisting from control varieties: Traminer roz $60 \mathrm{Bl}$., Fetească regală $21 \mathrm{Bl}$., Pinot gris $34 \mathrm{Bl}$.

The training system is Guyot with periodical replacement arms supported on vertical trellis with three double rows of wire, with planting distances of $2.0 \mathrm{~m}$ between rows and $1.2 \mathrm{~m}$ between plants in the row.

The way of block vine wintering was appreciated by controlling of buds viability (\%). Production capacity and grape harvest quality was calculated based on fertility (\%), the average weight of bunch grapes (g), grape production per vine block, weight of 100 berries, sugar content $(\mathrm{g} / \mathrm{l}$ must) the total acidity $\left(\mathrm{g} / \mathrm{l} \mathrm{H}_{2} \mathrm{SO}_{4}\right.$ must). The attack degree of main diseases and pests (downy mildew, powdery mildew, grey mold, mites and moths of grapes) was based on frequency (F\%) and intensity (I\%) of attack degree and noted according to logarithmic scale used by International Organisation of Vine and Wine (OIV).

\section{RESULTS AND DISCUSSION}

The ampelographic characters of studied genotypes and compared with reference varieties are presented in Figures 1-3.

Climatic conditions of the two experimental years (2012 and 2013) were very different, in these years registering maximum and minimum absolute temperatures that have jeopardized the proper development of physiological processes. In the rest period (January-February) of 2012 there were absolute minimum temperatures below $-20^{\circ} \mathrm{C}$ for several days consecutive affecting the buds viability (Table 1 ).

In these conditions the 5-26 elite proved to have good resistance to frost (52\%), but lower than the control (Traminer roz 60Bl.). 11-26 elite under stressful conditions (frost) behaved similarly to the control, recording a viability over $79 \%$, but this elite in normal years recorded values greater than Fetească regală 21Bl. Compared to this variety of reference for Târnave vineyard (Fetească regală), 1749 clonal elite recorded a lower value (64\%), giving evidence of a higher sensitivity to this disturbing factor being affected fertility of genotype (Table 2).

Tab. 1. The climate characterization of Târnave Vineyard in the 2012-2013 periods

\begin{tabular}{lcc}
\hline \multirow{2}{*}{ Ecoclimatic elements } & \multicolumn{2}{c}{ Values of the climatic factors } \\
\cline { 2 - 3 } & 2012 & 2013 \\
\hline Average annual temperature $\left({ }^{\circ} \mathrm{C}\right)$ & 10.5 & 11.1 \\
\hline Air maximum temperature $\left({ }^{\circ} \mathrm{C}\right)$ & +41.6 & +38.8 \\
\hline Air minimum temperature $\left({ }^{\circ} \mathrm{C}\right)$ & -21.6 & -13.7 \\
\hline$\sum$ Annual rainfalls $(\mathrm{mm})$ & 491.4 & 669.4 \\
\hline$\sum$ Rainfalls during the vegetation period $(\mathrm{mm})$ & 340.8 & 441.0 \\
\hline$\sum$ Sunstroke hours (hours) & 2113.1 & 2001.5 \\
\hline$\sum$ Sunstroke hours during vegetations period (hours) & 1602.0 & 1317.6 \\
\hline Global thermal balance $\left(\sum \mathrm{t}^{\circ} \mathrm{g}\right)$ & 3546.3 & 3202.0 \\
\hline Active thermal balance $\left(\sum \mathrm{t}^{\circ} \mathrm{a}\right)$ & 3546.0 & 3158.0 \\
\hline Useful thermal balance $\left(\sum \mathrm{t}^{\circ} \mathrm{u}\right)$ & 1875.0 & 1522.0 \\
\hline
\end{tabular}

Tab. 2. The agrobiologic characters of genotypes studied, in 2012-2013, at SCDVV Blaj

\begin{tabular}{ccccc}
\hline \multirow{2}{*}{ Genotypes } & \multicolumn{2}{c}{ Viability (\%) } & \multicolumn{2}{c}{ Fertility (\%) } \\
& 2012 & 2013 & 2012 & 2013 \\
\hline Hybrid elite 5-26 & 52.0 & 90.5 & 46.0 & 71.0 \\
Traminer roz 60 Bl.- control & 60.0 & 90.5 & 50.0 & 76.0 \\
\hline Hybrid elite 11-26 & 79.5 & 88.9 & 90.0 & 79.0 \\
Fetească regală 21 Bl.-control & 79.5 & 82.9 & 91.0 & 93.0 \\
Clonal elite 17-49 & 64.0 & 90.6 & 59.0 & 72.0 \\
\hline Clonal elite 18-11 & 70.0 & 89.8 & 61.0 & 50.0 \\
Pinot gris 34 Bl.-control & 70.5 & 90.6 & 72.0 & 69.0 \\
\hline
\end{tabular}




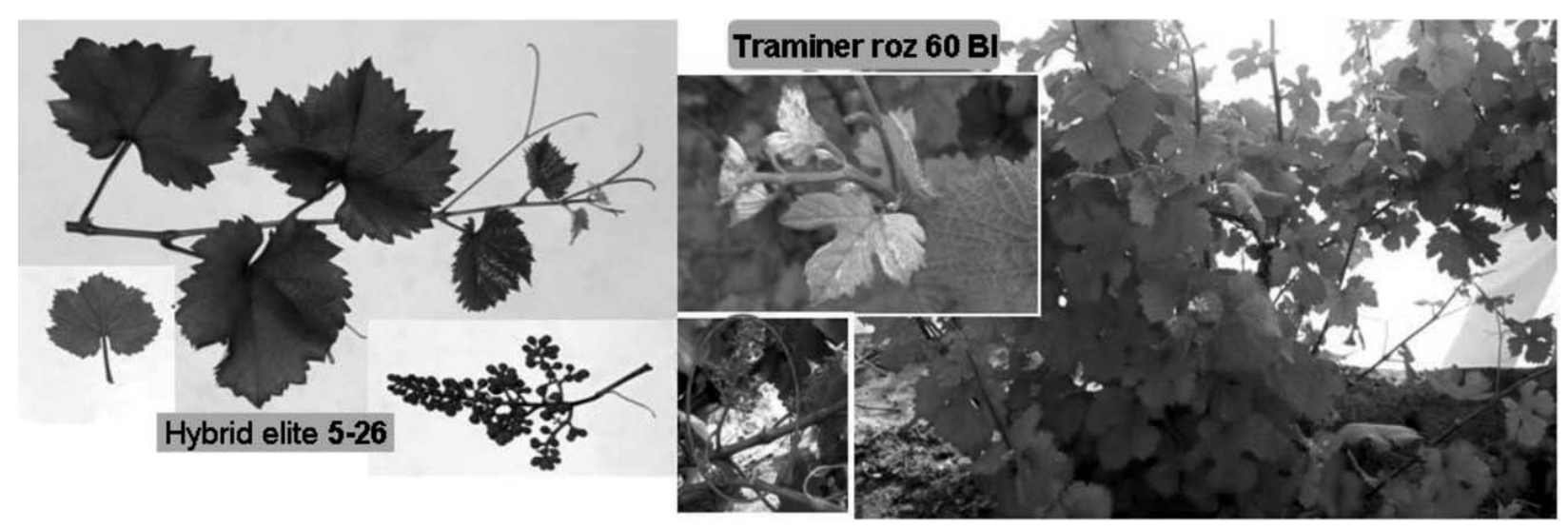

Fig. 1. Ampelographic characters of 5-26 hybrid elite (left) compared with control variety (right)
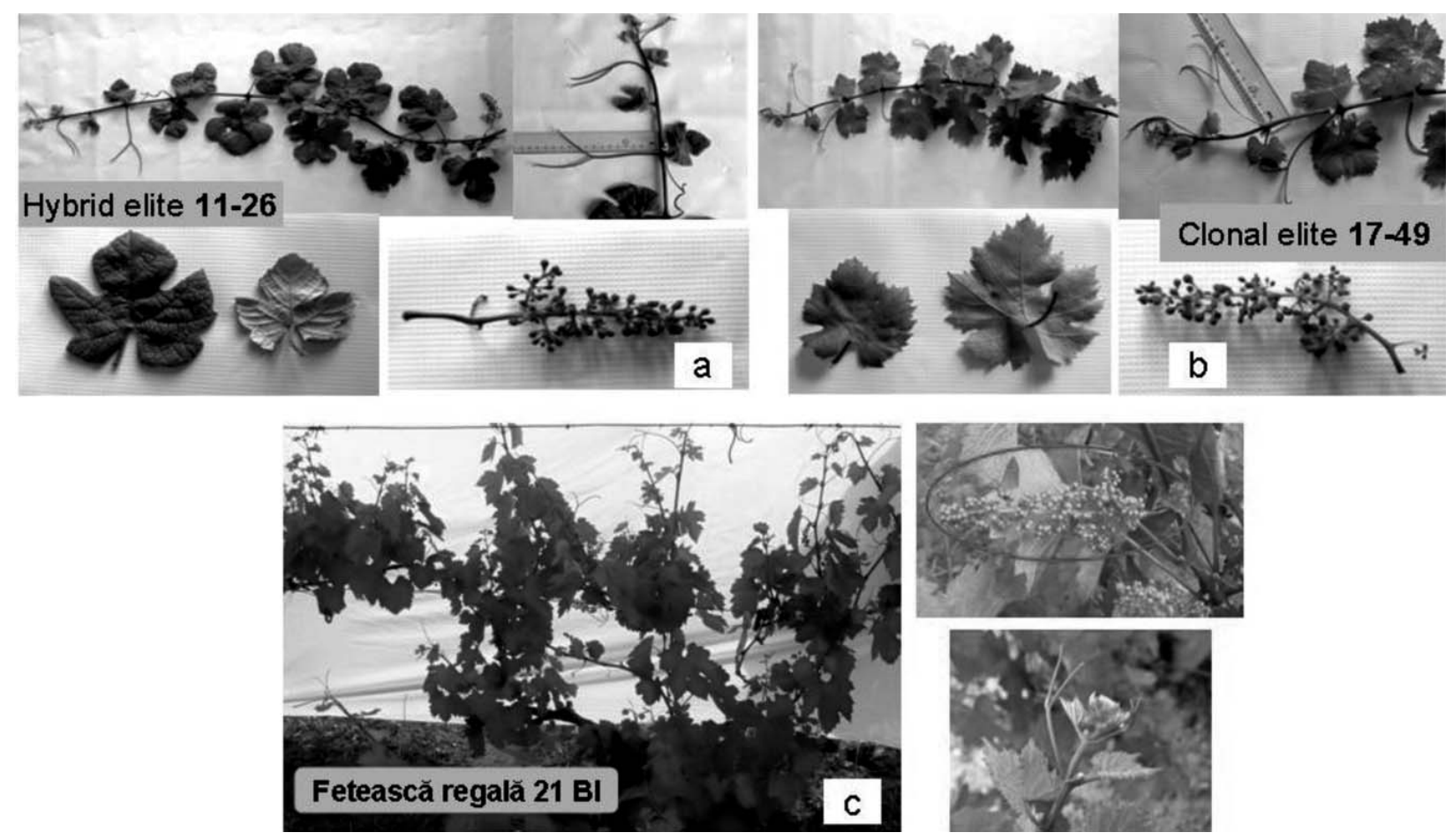

Fig. 2. Ampelographic characters of 11-26 hybrid elite (a) and 17-49 clonal elite (b) compared with control variety (c)

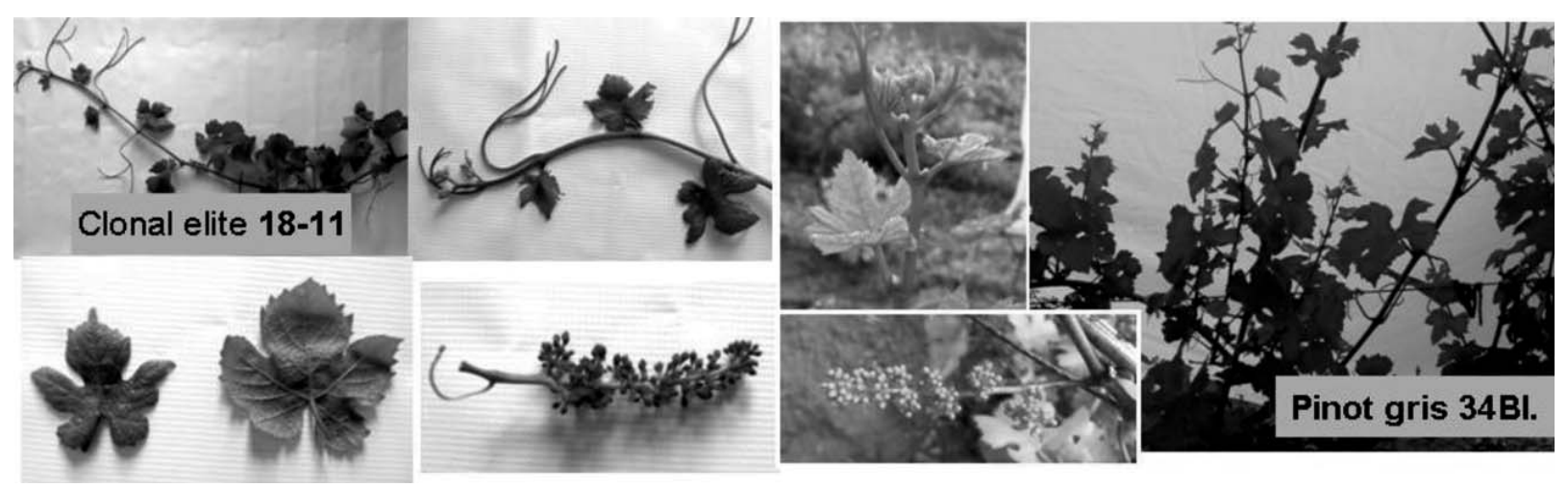

Fig. 3 .Ampelographic characters of 18-11 clonal elite (left) compared with control variety (right) 
The length of the vegetation period of the two experimental years was directly influenced by climatic conditions. Since in the period of vegetation of 2012 were registered higher temperatures than the normal and an absolute maximum temperature of $+41.6^{\circ} \mathrm{C}$, full maturation of the grapes, in all genotypes studied, was realized about two weeks earlier than the period specified for this area (Fig. 4).

In the year 2013, the first frost of autumn was registered in early of October, the length of the vegetation period was approximately 166-170 days. Moreover, during the maturation a higher amount of precipitation was registered, the grape genotypes studied have reached at full maturity at the end of September - early October.

Average weight of grapes (g) is a very important character that is both a productivity factor and an element of quality grapes. In our case, for de genotypes for wine analysis, during two years' experience, results are presented in Table 3.

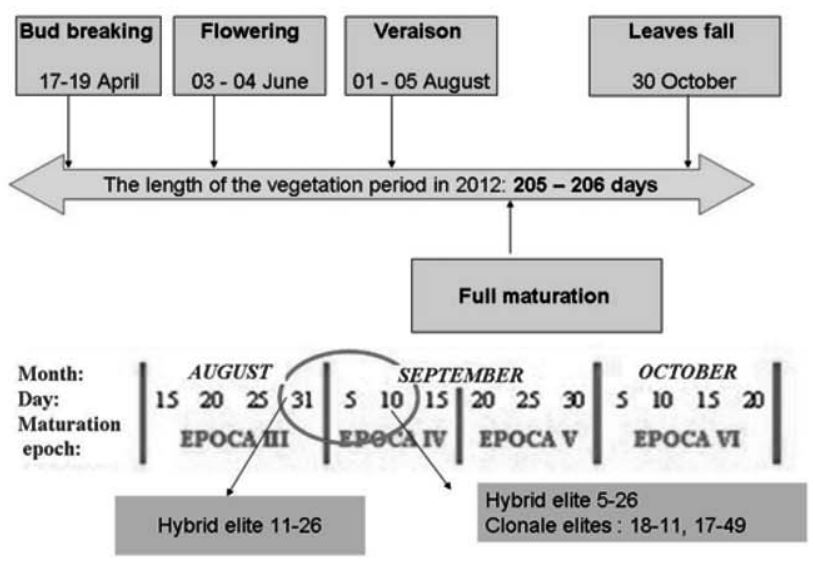

Hybrid elite 5-26 achieved an average weight of a grape higher than the control, the differences between the two wine years is given by climatic conditions. And the 11-26 elite realized an average weight of grape superior to control (Fetească regală $21 \mathrm{Bl}$.) this being constant in the two experimental years. Thus, this genotype is distinguished by stability of character to abiotic factors.

Clonal elite 17-49 registered under stressful conditions a weight grape (106.1 g) as a value close to control (108.2 g), but in normal years for vine growing this genotype recorded a higher value (167.4 g) than the variety of origin.

Clonal elite 18-11 record higher values then variety of origin (90.3-98.0 g), regardless of the stressors (climatic conditions).

Regarding the productivity of genotypes studied, all showed a lower production on the vine in 2012 compared to 2013; these values are given by low viability of buds and implicitly the low's fertility (Table2).

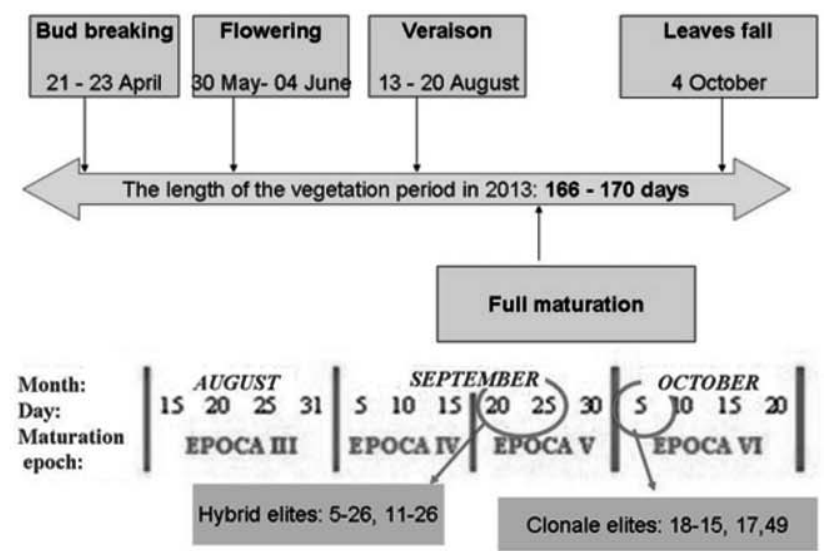

Fig. 4. The evolution of the main phenological phases in 2012 (left) and 2013(right), at SCDVV Blaj

Tab. 3. The productivity of genotypes in 2012 and 2013

\begin{tabular}{|c|c|c|c|c|}
\hline \multirow{2}{*}{ Genotypes } & \multicolumn{2}{|c|}{ Average weight of a grape bunch } & \multicolumn{2}{|c|}{ Production of grapes per vine $(\mathrm{kg})$} \\
\hline & 2012 & 2013 & 2012 & 2013 \\
\hline Hybrid elite 5-26 & 124.1 & 165.5 & 1.98 & 3.97 \\
\hline Traminer roz 60 Bl.- control & 91.8 & 112.6 & 1.01 & 2.64 \\
\hline Hybrid elite 11-26 & 211.5 & 211.5 & 0.65 & 4.65 \\
\hline Fetească regală 21 Bl.-control & 108.2 & 147.6 & 2.14 & 2.14 \\
\hline Clonal elite 17-49 & 106.1 & 167.4 & 3.59 & 3.68 \\
\hline Clonal elite 18-11 & 92.6 & 122.6 & 2.03 & 3.33 \\
\hline Pinot gris $34 \mathrm{Bl}$-control & 90.3 & 98.0 & 2.03 & 2.84 \\
\hline
\end{tabular}


Analysing the quality of harvest, the results achieved by the genotypes studied are shown in Tabel 4.

In 2012-2013, the three varieties taken as controls (Traminer roz $60 \mathrm{Bl}$, Pinot gris $34 \mathrm{Bl}$ and Fetească regală $21 \mathrm{Bl}$.) recorded similar values regarding quality and quantity of harvest to those presented by Grecu (2010) and Cudur et al (2014), for Târnave vineyard.

Regarding the quality characteristics 5-26 elite is distinguished through higher sugar content in the must compared with Traminer roz $60 \mathrm{Bl}$, grape berries are larger and total acidity of its must is $4.08-4.10 \mathrm{~g} / \mathrm{l} \mathrm{H}_{2} \mathrm{SO}_{4}$. The must made from this genotype is balanced.
Among the clonal elite was noted elite 18-11, who recorded an amount of sugars in the must higher than Pinot gris $34 \mathrm{Bl}$., over 226 g/l, even under abundant precipitation conditions during ripening. Total acidity was constant in must, being situated between 4.11-4.12 $\mathrm{g} / \mathrm{l} \mathrm{H}_{2} \mathrm{SO}_{4}$.

Analyzing the resistance of studied genotypes to the main diseases of the vine, they showed a high resistance to downy mildew (Plasmopara viticola) and powdery mildew (Uncinula necator) and moderate resist to grey rot (Botrytis cinerea) (Table 5).

Regarding their behaviour to attack of the main pests of the vine (grape moth: Lobesia botrana and mites: Calepitrimerus vitis, Tetranychus urticae, Eriophyes vitis) genotypes showed a high resistance.

Tab. 4. The quality of harvest at genotypes studied in 2012 and 2013

\begin{tabular}{lcccccc}
\hline \multirow{1}{*}{\multicolumn{1}{c}{ Genotypes }} & \multicolumn{2}{c}{$\begin{array}{c}\text { Weight of 100 grape } \\
\text { grains (g) }\end{array}$} & \multicolumn{2}{c}{$\begin{array}{c}\text { Sugar content of } \\
\text { must }(\mathrm{g} / \mathrm{l})\end{array}$} & \multicolumn{2}{c}{ Total acidity } \\
& $\left.\mathrm{g} / \mathrm{l} \mathrm{H}_{2} \mathrm{SO}_{4}\right)$ \\
& 2012 & 2013 & 2012 & 2013 & 2012 & 2013 \\
\hline Hybrid elite 5-26 & 162.1 & 130.5 & 236.3 & 204.1 & 4.08 & 4.10 \\
Traminer roz 60 Bl.- control & 151.7 & 111.0 & 223.1 & 198.0 & 3.53 & 3.92 \\
\hline Hybrid elite 11-26 & 130.1 & 128.5 & 194.1 & 188.8 & 5.00 & 4.13 \\
Fetească regală 21 Bl.-control & 168.0 & 178.1 & 210.7 & 205.2 & 5.13 & 5.27 \\
Clonal elite 17-49 & 129.6 & 170.4 & 177.2 & 211.2 & 4.80 & 3.92 \\
\hline Clonal elite 18-11 & 129.6 & 132.7 & 229.6 & 226.2 & 4.11 & 4.12 \\
Pinot gris 34 Bl.-control & 141.2 & 103.0 & 212.6 & 219.0 & 4.83 & 3.92 \\
\hline
\end{tabular}

Tab. 5. Genotypes response to biotic stress factors (diseases and pests)

\begin{tabular}{|c|c|c|c|c|}
\hline Genotypes & Disease / Pest & Note & $\begin{array}{l}\text { The average of } \\
\text { infestation } \\
\text { Logarithmic scale }\end{array}$ & Description \\
\hline \multirow{5}{*}{$\begin{array}{l}\text { Hybrid elite 5-26 } \\
\text { Hybrid elite 11-26 }\end{array}$} & Plasmopara viticola & 3 & $2-4$ & Resistant \\
\hline & Uncinula necator & 3 & $2-4$ & Resistant \\
\hline & Botrytis cinerea & 4 & $4-7$ & Moderate resistant \\
\hline & Lobesia botrana & 3 & $2-4$ & Resistant \\
\hline & $\begin{array}{l}\text { Calepitrimerus vitis, } \\
\text { Tetranychus urticae, } \\
\text { Eriophyes vitis }\end{array}$ & 3 & $2-4$ & Resistant \\
\hline \multirow{5}{*}{$\begin{array}{l}\text { Clonal elite 17-49 } \\
\text { Clonal elite 18-11 }\end{array}$} & Plasmopara viticola & 3 & $2-4$ & Resistant \\
\hline & Uncinula necator & 3 & $2-4$ & Resistant \\
\hline & Botrytis cinerea & 4 & $4-7$ & Moderate resistant \\
\hline & Lobesia botrana & 3 & $2-4$ & Resistant \\
\hline & $\begin{array}{l}\text { Calepitrimerus vitis, } \\
\text { Tetranychus urticae, } \\
\text { Eriophyes vitis }\end{array}$ & 3 & $2-4$ & Resistant \\
\hline
\end{tabular}




\section{CONCLUSION}

Hybrid elites studied had good behaviour with good value sugar/acidity/production ratio. Of clonale elites, 18-11 was remark from qualitative point of view since has accumulated the greatest amount of sugars, with a good sugar/acidity ratio. Regarding the productivity, 17-49 clonale elite it is noted for obtained the highest yield in detriment of quality, the wines that are obtained from this clone being for current consumption or for mixing.

Because from clonale elite 18-11 Pinot gris and 5-26 hybrid elite can be obtained superior quality wines according to DOC category, with a potential alcoholic over $12.5 \%$ vol., even in less favourable climatic conditions for vine culture, these will be proposed for homologation.

\section{REFERENCES:}

1. Călugăr A, Pop N, Farago M, Babeş A, Bunea C, Hodor D, Ciobanu F (2010). The estimation of growth-yield balance indices at Astra, Blasius, Selena and Fetească regală, in Târnave Vineyard. Journal of Horticulture, Forestry and Biotechnology, Volume 14(3):11-16.

2. Călugăr A (2011). Research regarding the behaviour of some grapes varieties for white wines created at S.C.D.V.V.
Blaj, in Târnave Vineyard conditions. PhD Thesis, UASMV Cluj Napoca.

3. Cudur F, Iliescu M, Comşa M, Popescu D, Cristea C (2014). Soil type influence on yield quantity and quality at grape varieties for white wines obtained in the viticultural centre Blaj. Bulletin of UASMV Cluj-Napoca, Horticulture, Vol. 71(1): 21-28.

4. Grecu V (2010). Resistant grapevine varieties and their cultural particularities. Ed. M.A.S.T., pg: 29-31.

5. Iliescu M, Farago M, Pop N (2010). Studies on the behaviour of the main grape varieties for white wine, in SCDVV Blaj. Bulletin UASMV Horticulture 67(1):495.

6. Oprea S, Moldovan SD (2007). The plant breeding of grapevine. Ed. Poliam, Cluj Napoca.

7. Sestras R. (2004). The plant breeding of horticultural species. Ed. AcademicPres, Cluj Napoca.

8. Tóth-Lencsés K, Cocco M, Németh G, Rustioni L, Kerekes A, Kiss E, Kocsis L (2014). Phenotyping under extreme weather conditions and microsatellite based genotyping of some Hungarian grape cultivars. Book of Abstract, pg: 34. Cost Action FA1003 - GRAPENET East-West Collaboration for Grapevine Diversity Exploration and Mobilization of Adaptive Traits for Breeding.

9. Wiedemann-Merdinoglu S, Dumas V, Dorne MA, Lacombe MC, Duchene E, Mestre P, Merdinoglu D (2014). High throughput phenotyping of a Vitis vinifera collection for downy and powdery mildews. Book of Abstract, pg: 36. Cost Action FA1003 - GRAPENET. 